\title{
A Novel Integrated Hydrothermal Liquefaction and Solar Catalytic Reforming Method for Enhanced Hydrogen Generation from Biomass
}

\author{
Anuradha Shende, Richa Tungal, Rajneesh Jaswal, Rajesh Shende* \\ Department of Chemical and Biological Engineering, South Dakota School of Mines \& Technology, Rapid City, South Dakota, USA \\ *Corresponding author: rajesh.shende@sdsmt.edu
}

Received January 31, 2015; Revised February 21, 2015; Accepted February 27, 2015

\begin{abstract}
Short energy intensive hydrothermal liquefaction (HTL) of biomass in the presence of Ni salt catalyst selectively generates $\mathrm{H}_{2}$ in the product gas and biocrude mainly containing $\mathrm{C}_{1}-\mathrm{C}_{3}$ acids (formic, lactic, propionic, acetic), HMF and furfural. The $\mathrm{H}_{2}$ mass balance indicated that only $3.12 \mathrm{vol} \% \mathrm{H}_{2}$ in biomass (cotton) was released as product gas; 48.7 vol\% was captured in the $\mathrm{C}_{1}-\mathrm{C}_{3}$ acids while the remainder $\mathrm{H}_{2}$ was trapped in oxygenated compounds and char. Continuing HTL after 120 minutes caused no further increase in gas phase $\mathrm{H}_{2}$ yields. To enhance the $\mathrm{H}_{2}$ yields with minimal energy input, solar photocatalytic reforming (PR) of the biocrude with $\mathrm{Pt} / \mathrm{TiO}_{2}$ catalyst was investigated. Photocatalysis of activated carbon (AC) treated biocrude generated an additional $\mathrm{H}_{2}, 17.82$ wt\%. $\mathrm{H}_{2}$ yields from photoreforming of simulated biocrude acid mixture and actual biocrude were compared. Enhanced $\mathrm{H}_{2}$ generation was observed with integrated HTL-PR of biomass.
\end{abstract}

Keywords: hydrogen, hydrothermal liquefaction, cotton, photoreforming, biocrude

Cite This Article: Anuradha Shende, Richa Tungal, Rajneesh Jaswal, and Rajesh Shende, "A Novel Integrated Hydrothermal Liquefaction and Solar Catalytic Reforming Method for Enhanced Hydrogen Generation from Biomass.” American Journal of Energy Research, vol. 3, no. 1 (2015): 1-7. doi: 10.12691/ajer-3-1-1.

\section{Introduction}

World's current energy demand is primarily fulfilled by the use of fossil fuels, however, very little fraction of energy is derived from renewable resources [1]. Biomass is a renewable source of environmentally friendly high energy density $(142 \mathrm{MJ} / \mathrm{kg})$ hydrogen $\left(\mathrm{H}_{2}\right)$ fuel. In industry, majority of $\mathrm{H}_{2}$ is produced by steam reforming of non-renewable resources such as the natural gas and petroleum. With rapid depletion of these resources, many researchers are exploring biological [2], pyrolysis [3], gasification [4], hydrothermal liquefaction (HTL) [5,6] and photoreforming $[7,8]$ processes for $\mathrm{H}_{2}$ generation from renewable biomass, biomass waste and biomass components. However, each of these technologies suffer from drawbacks ranging from high energy input to low conversion efficiencies pointing to a need to develop energy efficient viable routes for $\mathrm{H}_{2}$ generation from renewable sources.

Hydrothermal liquefaction (HTL) under subcritical conditions transforms a biomass into gaseous products, liquid biocrude and solid biochar. The composition of the biocrude and product gas is largely influenced by catalyst. In our previous work [9] on HTL of cellulose, xylan, lignin, wastepaper and pinewood, homogeneous $\mathrm{Ni}$ salt catalysts were found effective in generating $\mathrm{H}_{2}$. HTL of pinewood at $275^{\circ} \mathrm{C}$ with $\mathrm{Ni}\left(\mathrm{NO}_{3}\right) 2$ yielded $12.26 \mathrm{~mol} \%$ $\mathrm{H}_{2}$ [6]. Under similar experimental conditions, the authors reported HTL of wastepaper resulted in 51\% liquefaction with $10.2 \mathrm{~mol} \% \mathrm{H}_{2}$ generation [5]. These HTL studies revealed longer processing time that resulted only in slight increase in $\mathrm{H}_{2}$ yield with bicrude mainly forming $\mathrm{CO}_{2}$ in the product gas. Biocrude typically contains intermediates such as saccharides, anhydrosugars, HMF, furfural, ketones, alcohols, carboxylic acids, lignin derived compounds [5]. Our studies with pinewood and waste paper have shown that the Ni salt catalyst promotes higher quantities of $\mathrm{C}_{1}-\mathrm{C}_{3}$ carboxylic acids in the biocrude. Several $C_{1}-C_{3}$ acids have been shown to be excellent sacrificial agents in photocatalyis for $\mathrm{H}_{2}$ generation. There are many reports on photocatalysis of single acids for $\mathrm{H}_{2}$ production. For e.g. photoreforming of lactic, acetic, benzoic, formic and oxalic acids has been investigated with the aim of simultaneous $\mathrm{H}_{2}$ production and remediation of acidic wastewater $[10,11,12]$. However, $\mathrm{H}_{2}$ yields from few real multi-component aqueous systems have been studied [13,14]. Photoreforming of wastewater systems containing multiple electron donors showed that the $\mathrm{H}_{2}$ yields depend on several factors such as $\mathrm{TiO}_{2}$ surface adsorption, chemical structure, concentration and the ratio of the electron donors [10]. To the best of our knowledge, photocatalysis of the complex multicomponent biocrude for $\mathrm{H}_{2}$ production is not yet reported.

In addition to acids and sugars, HTL derived biocrude contains several other compounds that may either contribute to the $\mathrm{H}_{2}$ yield or may negatively affect photoreforming process. Lignin, tannin, and sugars interfering in downstream processes such as the microbial 
fermentation have been removed using activated charcoal (AC) $[15,16]$. AC has also been used to remove toxic components from biocrude obtained from HTL of starch for downstream microbial processing [17]. Therefore, in this investigation, cotton biocrude was treated with AC to remove potential interfering compounds. Both, untreated and AC-treated biocrude were tested with PR process for the $\mathrm{H}_{2}$ generation.
Chemically inert and inexpensive $\mathrm{TiO}_{2}$ catalyst [18] was chosen for PR of biocrude. The band gap energy $\left(E_{g}\right)$ of $\mathrm{TiO}_{2}$ permits excitation of $\mathrm{TiO}_{2}$ only by the $\mathrm{UV}$-portion of the solar spectrum. Efforts can be found in the literature on modifying $\mathrm{TiO}_{2}$ with suitable dopants to achieve visible light activation. Very recently, we reported $\mathrm{TiO}_{2}$ modified $\mathrm{ZnO} / \mathrm{TiO}_{2}$ photocatalysts [19] with lower $E_{g}$ that yielded higher $\mathrm{H}_{2}$ volume from aqueous methanol.

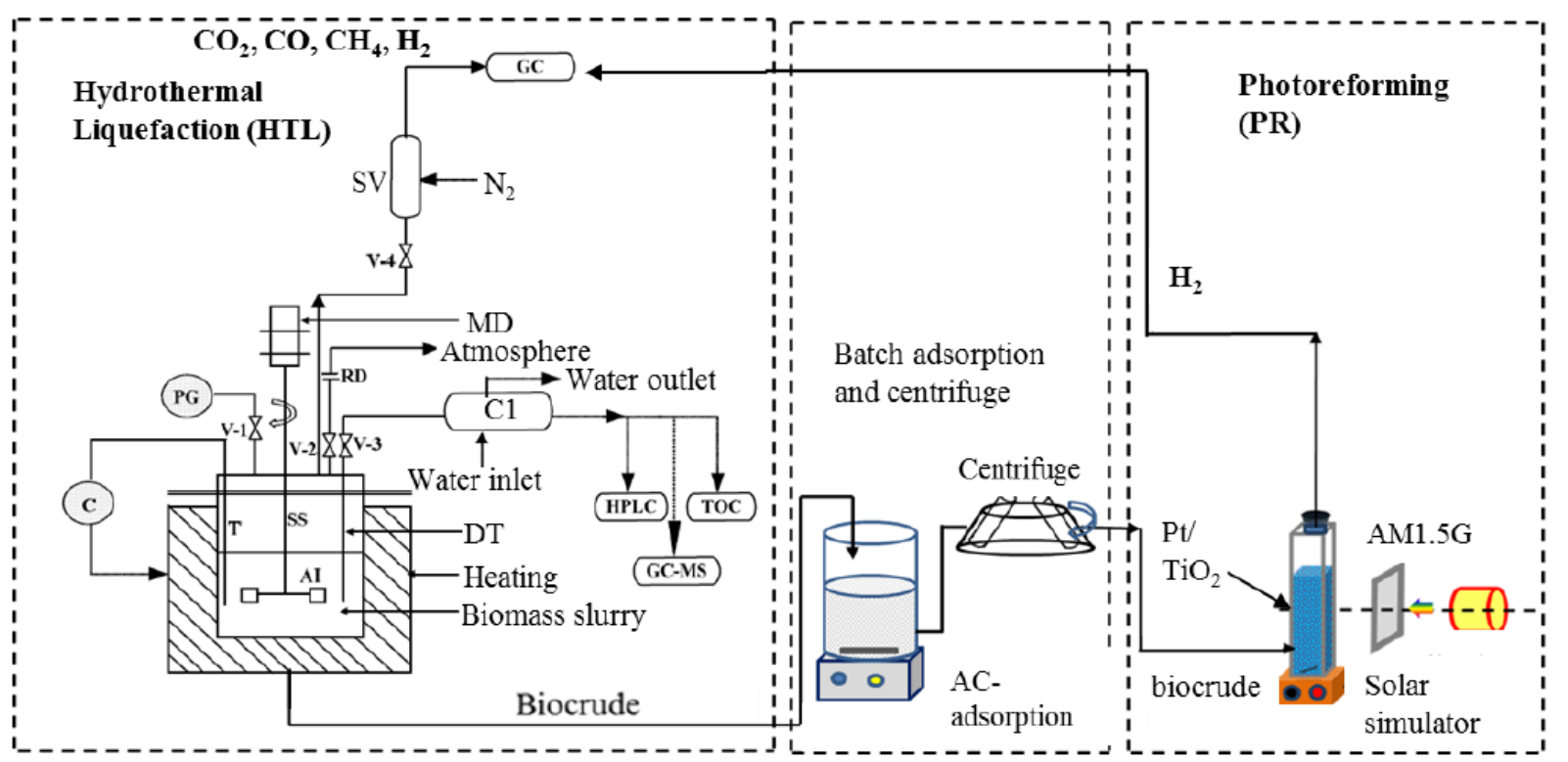

Figure 1. Schematic of integrated hydrothermal liquefaction (HTL) and photoreforming (PR) process for $\mathrm{H}_{2}$ generation (GC: gas chromatography, GCMS: gas chromatography-mass spectrometry, HPLC: high pressure liquid chromatography, TOC: total organic carbon, MD: magnetic drive, RD: rupture disk, SS: stainless steel, C: cooling water, C1: condenser, PG: pressure regulator, V1/V2/V3/V4: control needle valves, T: thermocouple, W: vessel SS304 mounted for gas sampling, AI: impeller)

Additionally, the rapid recombination of the photogenerated electrons with the holes limits $\mathrm{H}_{2}$ production. Using co-catalyst such as platinum on $\mathrm{TiO}_{2}$ surface traps photogenerated electrons and partially prevents electron-hole recombination [20]. The PR of biomass model compounds, such as the primary, secondary and tertiary alcohols, glycerol, sugars and a few carboxylic acids have been studied for $\mathrm{H}_{2}$ generation [21]. It is expected that $\mathrm{H}_{2}$ and $\mathrm{CO}_{2}$ production from biocrude components will follow the general reforming scheme:

$$
\mathrm{C}_{x} \mathrm{H}_{y} \mathrm{O}_{z}+(2 x-z) \mathrm{H}_{2} \mathrm{O} \stackrel{h v}{\longrightarrow} x \mathrm{CO}_{2}+(2 x-z+y / 2) \mathrm{H}_{2}
$$

Green solar photoreforming of the biocrude to $\mathrm{H}_{2}$ will not only remediate the biocrude but also permit significantly higher $\mathrm{H}_{2}$ abstraction from the biomass. In this study, HTL of cellulosic biomass was carried out at $250^{\circ} \mathrm{C}$ in the presence of $\mathrm{NiSO}_{4}$ catalyst for the production of $\mathrm{H}_{2}$ and biocrude containing $\mathrm{C}_{1}-\mathrm{C}_{3}$ carboxylic acids. The biocrude and its carboxylic acids were individually photoreformed to demonstrate additional yields of $\mathrm{H}_{2}$. A schematic describing the combined HTL and PR process is shown in Figure 1. The results show that integrated HTL and PR process has a potential to develop into technologically feasible route for enhanced $\mathrm{H}_{2}$ production.

\section{Materials and Methods}

\subsection{Materials}

Commercially available cotton balls (98\% cellulose) were selected as biomass feedstock. Nickel sulphate hexahydrate and dihydrogen hexachloroplatinate (IV) hydrate, Premion (99.999\% metal basis) were purchased from Alfa Aesar, MA. Titanium (IV) oxide (P25 nanoparticles), 99.7\% anatase (particle size $\sim 25 \mathrm{~nm}$, surface area $45-55 \mathrm{~m}^{2} / \mathrm{gm}$ ) was obtained from Sigma Aldrich. Filtrasorb 600 activated charcoal (Iodine number $850 \mathrm{mg} / \mathrm{g}$ ) was purchased from Calgon Carbon.

\subsubsection{Elemental Composition of Biomass}

Biomass, cotton (1 gram) was dried at $45^{\circ} \mathrm{C}$ overnight in the oven and weighed the next day to determine moisture content. The moisture free cotton was supplied to the Midcontinent Testing Labs, Inc., Rapid City, SD, USA for the elemental analysis.

\subsubsection{Preparation of Platinum Coated $\mathrm{TiO}_{2}$ Nanoparticles}

Platinum coating on $\mathrm{TiO}_{2}$ nanoparticles was achieved by the wet incipient method. $\mathrm{TiO}_{2}$ nanoparticles $(0.5 \mathrm{~g})$ were placed in water $(12 \mathrm{ml})$ and sonicated for $30 \mathrm{~min}$. To this dispersion, hexachloroplatinic acid (1 wt\% Pt equivalent) was added and sonication was continued for additional 3 hrs. The dispersion was dried at $100^{\circ} \mathrm{C}$ and calcined at $600^{\circ} \mathrm{C}$ for 1 hrs. The platinum loading was determined by EDX analysis using Zeiss Supra 40VP scanning electron microscope/energy dispersive X-ray spectrometer.

\subsubsection{Hydrothermal Liquefaction (HTL) of Biomass}

A $300 \mathrm{ml}$ high-temperature, high-pressure (HTHP) stainless steel (SS316) reactor (PARR Instrument Co, 
Illinois) fitted with gas inlet, outlet valves, a liquid sampling valve, pressure gauge, rupture disc, magnetic drive and a thermocouple was used for HTL of biomass. Slurry of 1.0 gram cotton balls cut into $0.5 \mathrm{~cm}^{2}$ pieces was made in $150 \mathrm{ml}$ of distilled water containing $5 \mathrm{wt} \% \mathrm{NiSO}_{4}$ catalyst. The slurry was loaded in the reactor and stirred by an impeller at a constant speed of $1300 \mathrm{rpm}$. The reactor was pressurized to $40 \mathrm{psi}$ with $\mathrm{N}_{2}$ at room temperature and heated to $250^{\circ} \mathrm{C}$ to perform HTL for 120 min. During the HTL processing, gas and liquid samples were withdrawn periodically and analyzed by GC, HPLC and GC-MS. The processed slurry was centrifuged at $13000 \mathrm{rpm}$ for $20 \mathrm{~min}$ to recover supernatant biocrude.

\subsubsection{Characterization of Product Gas from HTHP Reactor Headspace}

While HTL of biomass was in progress, product gas samples were withdrawn from the HTHP reactor headspace and analyzed on the Agilent7890A gas chromatograph (GC) equipped with thermal conductivity detector (TCD) and Porapak-Q stainless steel packed column (6 ft x 0.25 in x $2.1 \mathrm{~mm}$ ) from Supelco. The GC oven was operated at $40^{\circ} \mathrm{C}$ and $\mathrm{N}_{2}$ at $1 \mathrm{ml} / \mathrm{min}$ was used as a carrier gas. He $(99.99 \%$ purity) was used to characterize gaseous carbon species. Calibration curves were prepared using specific gas standards purchased from the Matheson Gases, SD, USA and the product gas volumes were determined at the NTP $\left(20^{\circ} \mathrm{C}\right.$ and $\left.1 \mathrm{~atm}\right)$ conditions.

\subsubsection{Activated Carbon (AC) Treatment of Biocrude and Characterization of AC-treated Biocrude}

To the biocrude obtained from HTL, activated carbon was added at two different concentrations of $10 \mathrm{mg} / \mathrm{ml}$ and $50 \mathrm{mg} / \mathrm{ml}$. The mixture was left on a stirrer for 12 hours after which it was centrifuged. The clear supernatant was kept at $4^{\circ} \mathrm{C}$ until ready to use. The biocrude was analyzed on a HPLC (Shimadzu) equipped with Rezex ROA 300 × $7.8 \mathrm{~mm}$ column and UV-vis detector. A mobile phase of $0.005 \mathrm{M} \mathrm{H}_{2} \mathrm{SO}_{4}$ was used. Ethyl acetate extract of the biocrude was analyzed on an Agilent GCMS (7890 GC/5975C MSD) equipped with Agilent HP$5 \mathrm{~ms}$ capillary column. Helium (99.999\%, UHP grade) with column flow rate of $1.197 \mathrm{ml} / \mathrm{min}$ was used as carrier gas. The oven was programmed as follows: $40^{\circ} \mathrm{C}(8 \mathrm{~min}$ hold), ramped up $\left(2^{\circ} \mathrm{C} / \mathrm{min}\right)$ to $120^{\circ} \mathrm{C}$ (8 $\mathrm{min}$ hold $)$, ramped up $\left(5^{\circ} \mathrm{C} / \mathrm{min}\right)$ to $220^{\circ} \mathrm{C}$ (no hold) and $\left(20^{\circ} \mathrm{C} / \mathrm{min}\right)$ to $250^{\circ} \mathrm{C}$ (no hold). The temperature of injector and detector was maintained at $300^{\circ} \mathrm{C}$. The compounds were identified using National Institute of Standards and Technology (NIST) mass spectral library (2008, version 2.0f). The total organic carbon (TOC) content of the ACtreated HTL derived cotton biocrude was determined using a Sievers InnovOx Laboratory TOC analyzer (GE Instruments). Similar analyses were carried out with the samples of untreated.

\subsubsection{Photocatalytic Reforming (PR) of Biocrude and Carboxylic Acids to $\mathbf{H}_{2}$}

$\mathrm{Pt} / \mathrm{TiO}_{2}$ photocatalyst $(4.0 \mathrm{mg})$ was dispersed in $10 \mathrm{ml}$ de-ionized water for 30 minute using ultrasonic bath and the dispersion was purged with $\mathrm{N}_{2}$ for 30 min to displace oxygen. Lactic (LA), formic (FA), acetic (AA) and propionic (PA) acids were individually and in a mixed form dissolved in water to a final concentration of $50 \mathrm{mM}$. In another experiment LA, AA, FA PA were mixed in ratio of 3.65:1.80:1.27:1 to form biocrude acids stimulant. The reaction mixture $(7 \mathrm{ml})$ was added to a quartz reactor and sealed with a butyl septum. The reactor headspace (4 ml) was purged with $\mathrm{N}_{2}$. The headspace gas was sampled to confirm absence of $\mathrm{O}_{2}$. The mixture was stirred by a magnetic needle and exposed to simulated solar irradiation obtained with $240 \mathrm{~W}$ Xe lamp and AM1.5G filter. The power density measured at the center of the reactor window was $100 \mathrm{~mW} / \mathrm{cm}^{2}$. During PR, headspace gas was withdrawn periodically and analyzed for $\mathrm{H}_{2}$ on the Agilent 7890GC using the same column and method used for the analysis of product gas from HTL. Photreforming of ACtreated and untreated biocrude for $\mathrm{H}_{2}$ generation was carried out using the same procedure as described earlier for individual acid and acid mixture. To achieve maximal reforming of the biocrude to $\mathrm{H}_{2}$, the headspace was evacuated after 3 hour and purged with $\mathrm{N}_{2}$ prior performing the next photoreforming cycle. The photoreforming cycles were continued until $\mathrm{H}_{2}$ levels were below detection limit in GC analysis.

\section{Results and Discussion}

\subsection{HTL of Cotton in the Presence of $\mathrm{NiSO}_{4}$ Catalyst}

Elemental analysis of cotton revealed that $\mathrm{C}, \mathrm{H}, \mathrm{N}$ and O were 45 wt $\%, 7.11$ wt\%, 0.2 wt $\%$ and 47.69 wt\%, respectively. Figure 2a shows the product gas analysis from HTL of 1 gram cotton in the presence of $5 \mathrm{wt} \%$ $\mathrm{NiSO}_{4}$ at $250^{\circ} \mathrm{C}$ and 650 psi. At "zero" reaction time, practically no $\mathrm{H} 2$ was observed, however, after $60 \mathrm{~min}$ of reaction $4.3 \mathrm{ml} \mathrm{H}_{2}$ volume was detected. A total $\mathrm{H}_{2}$ volume of $11.54 \mathrm{ml}$ was observed after 120 min reaction time suggesting an almost linear increase in $\mathrm{H}_{2}$ volume generation. The concentration of $\mathrm{CH}_{4}$ in product gas was almost negligible at zero reaction time and did not change over the period of 2 hrs of reaction time. However, the volume of $\mathrm{CO}$ and $\mathrm{CO}_{2}$ observed at zero reaction was about $25 \mathrm{ml}$. As the reaction progressed further, the volume of CO increased to $28 \mathrm{ml}$ and remained constant.

Starting from zero reaction time to $2 \mathrm{hrs}$, the volumetric ratio of $\mathrm{H}_{2}$ : $\mathrm{CO}$ gaseous products increased from 0.0438 to 0.43 indicating 10 fold increase in $\mathrm{H}_{2}$ over CO. Thus it appears that $\mathrm{NiSO}_{4}$ has increased $\mathrm{H}_{2}$ selectivity in the product gas phase. It is to be noted that in the absence of catalyst negligible quantities of $\mathrm{H}_{2}$ were observed (data not shown). The $\mathrm{CO}_{2}$ volume observed at zero reaction time (25 ml) was increased to $33 \mathrm{ml}$ after 120 min reaction time. These results indicated 9.2\%, 23\% and 90\% (volume basis) increase in $\mathrm{CO}, \mathrm{CO}_{2}$ and $\mathrm{H}_{2}$, respectively over the period of 2 hrs reaction time at $250^{\circ} \mathrm{C}$. The total product gas was estimated to be $10 \mathrm{wt} \%$ of the 1 gram cotton that was processed at $250^{\circ} \mathrm{C}$ for 2 hrs. After the HTL, the reactor contents were cooled to room temperature and centrifuged to recover the biocrude and residue. Based on the TOC analysis of the biocrude $(1720 \mathrm{mg} / \mathrm{L})$ and carbon content of cotton (estimated TOC $2811 \mathrm{mg} / \mathrm{L}$ ), $61.2 \mathrm{wt} \%$ liquefaction of cotton was estimated (Figure 2b). The observed char residue was $28.8 \mathrm{wt} \%$. 

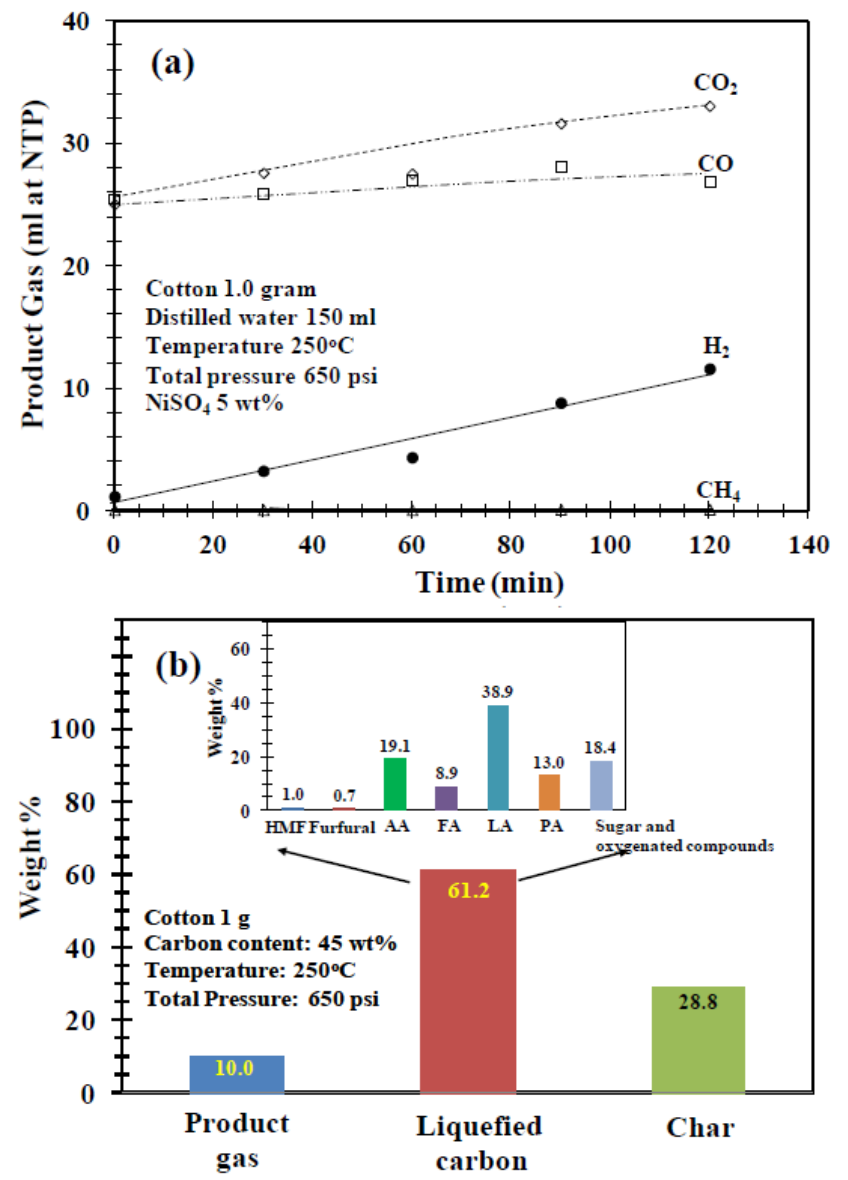

Figure 2. a) Product gas components observed during HTL of cotton at $250^{\circ} \mathrm{C}$ in the presence of $\mathrm{NiSO}_{4}$ catalyst and b) mass balance showing liquefied carbon, total product gas, and char

\subsection{Composition of the Cotton Biocrude}

The liquefied cotton biocrude was analyzed by HPLC and GC-MS and the results obtained are presented in Table 1 and Table 2, respectively. HPLC analysis revealed presence of acetic, formic, lactic and propionic acids. Among these acids, lactic acid is the main component with the concentration of $1675 \mathrm{mg} / \mathrm{L}$, whereas propionic acid was observed in minimum concentration of $459 \mathrm{mg} / \mathrm{L}$. The total acids were estimated to be $79.88 \mathrm{wt} \%$ of cotton biocrude as per the following equation-

$\%$ total acids

$$
=\frac{\sum\left(\text { carbon content of } C_{1} \text { to } C_{3} \text { acids observed }\right)}{\text { total liquefied carbon in biocrude }} \times 100
$$

Table 1. HPLC Analysis of $\mathrm{C}_{1}-\mathrm{C}_{3}$ acids in the Cotton Biocrude Obtained after $\mathrm{HTL}$ at $250^{\circ} \mathrm{C}$ in presence of $5 \mathrm{wt} \% \mathrm{NiSO}_{4}$

\begin{tabular}{|c|c|c|}
\hline $\mathbf{C}_{\mathbf{1}}-\mathbf{C}_{\mathbf{3}}$ acids, HMF, & \multicolumn{2}{|c|}{ Concentration $\left(\mathbf{m g L}^{\mathbf{- 1}}\right.$ ) } \\
\cline { 2 - 3 } Furfural & Biocrude & AC-treated biocrude \\
\hline Acetic acid & 824 & 40.4 \\
\hline Formic acid & 584 & 36.5 \\
\hline Lactic acid & 1675 & 348.3 \\
\hline Propionic acid & 459 & 39.6 \\
\hline HMF & 30.7 & ----- \\
\hline Furfural & 18.4 & ----- \\
\hline
\end{tabular}

HMF and furfural were observed to be $1.69 \mathrm{wt} \%$ of liquefied biocrude. The remaining $18.4 \mathrm{wt} \%$ of biocrude was assigned to $\mathrm{C}_{6}$ sugars (mainly glucose) and oxygenated hydrocarbons, which were thoroughly analyzed by GC-MS using HP-5ms column and inbuilt NIST library. The complete mass balance of different compounds observed in liquefied cotton biocrude is shown in Figure 2b. The GC-MS analysis of the biocrude showing only major compounds (peak area $>1 \%$ and confidence level $>95 \%$ ) is presented in Table 2. It indicates cyclic ketones and substituted cyclic ketones, quinone derivatives, phenols and substituted phenols, alcohols and acids. However, based on the mass balance analysis, it appears that the pathways leading to the formation of $C_{1}-C_{3}$ carboxylic acids dominated with the use of $\mathrm{NiSO}_{4}$ catalyst and under the experimental conditions employed.

Table 2. Major compounds observed in the biocrude and AC-treated biocrude as analyzed by GCMS; >95\% confidence level

\begin{tabular}{|c|c|c|c|}
\hline $\begin{array}{l}\text { Retention time } \\
\text { (min) }\end{array}$ & Compounds observed & $\begin{array}{l}\text { \% peak area } \\
\text { (biocrude) }\end{array}$ & $\begin{array}{l}\text { \% peak area } \\
\text { (AC-treated } \\
\text { biocrude) }\end{array}$ \\
\hline 6.25 & $\begin{array}{l}\text { 2-Butanol, 3-methyl-, } \\
\text { acetate }\end{array}$ & 0.916 & 10.32 \\
\hline 6.31 & $\begin{array}{c}\text { 1H-Pyrazole, 1,5- } \\
\text { dimethyl- }\end{array}$ & 17.074 & ---- \\
\hline 6.60 & 2-Butenoic acid, ethyl & 0.212 & 5.028 \\
\hline 6.75 & 2-Pentanol, acetate & 0.203 & 5.877 \\
\hline 6.93 & 2-Butanone & 1.482 & ---- \\
\hline 6.94 & Hexanal, 2-ethyl- & ----- & 2.007 \\
\hline 6.95 & $\begin{array}{l}\text { 5,9-Dodecadien-2-one, } \\
\text { 6,10-dimethyl-,(E,E))- }\end{array}$ & ---- & 1.772 \\
\hline 8.16 & $\begin{array}{l}\text { 2-Cyclopenten-1-one, 2- } \\
\text { methyl }\end{array}$ & 1.316 & 13.59 \\
\hline 8.28 & $\begin{array}{l}\text { Acetic acid, 1-ethyl-2- } \\
\text { methylpropyl ester }\end{array}$ & ----- & 1.080 \\
\hline 8.67 & $\begin{array}{l}\text { Hexanoic acid, 2- } \\
\text { propenyl ester }\end{array}$ & ----- & 2.297 \\
\hline 8.80 & 2-Pentenoic acid & 0.371 & 1.066 \\
\hline 9.26 & $\begin{array}{l}\text { 2(3H)-Furanone,dihydro- } \\
\text { 5-methyl }\end{array}$ & 10.693 & 38.79 \\
\hline 9.45 & $\begin{array}{c}\text { 2-Furancarboxaldehyde, } \\
\text { 5-methyl } \\
\end{array}$ & 1.353 & ----- \\
\hline 9.52 & $\begin{array}{l}\text { 2-Cyclopenten-1-one,3- } \\
\text { methyl }\end{array}$ & 1.098 & 0.560 \\
\hline 9.98 & $\begin{array}{c}\text { Formic acid, 2-propenyl } \\
\text { ester }\end{array}$ & ----- & 3.459 \\
\hline 9.99 & 2-Propen-1-ol & ----- & 3.680 \\
\hline 10.11 & Butanal, 2-methyl & 1.011 & ----- \\
\hline 10.82 & $\begin{array}{c}\text { 1,2-Cyclopentanedione, } \\
\text { 3-methyl }\end{array}$ & 5.893 & 3.124 \\
\hline 11.54 & Pentanoic acid, 4-oxo & 0.757 & 1.387 \\
\hline 12.48 & $\begin{array}{c}\text { 2-Cyclopenten-1-one, 3- } \\
\text { ethyl-2-hydroxy }\end{array}$ & 1.396 & ----- \\
\hline 15.07 & $\begin{array}{c}\begin{array}{c}\text { 1H-Inden-1-one, 2,3- } \\
\text { dihydro }\end{array} \\
\end{array}$ & 2.467 & ---- \\
\hline 16.31 & 1,2,3-Benzenetriol & 20.067 & ---- \\
\hline 17.54 & $\begin{array}{c}\text { Benzhydrazide, 3-nitro } \\
\text { N2-(4-pyridylmethylene)- }\end{array}$ & 1.889 & --- \\
\hline 17.85 & 1,2,4-Benzenetriol & 15.366 & ---- \\
\hline
\end{tabular}

\subsection{Activated Charcoal (AC) Treatment of Biocrude}

The cotton biocrude was treated with $10 \mathrm{mg} / \mathrm{ml}$ and 50 $\mathrm{mg} / \mathrm{ml}$ activated charcoal and the visible difference in biocrude coloration is shown in inset of Figure 3. Activated charcoal at $10 \mathrm{mg} / \mathrm{ml}$ did not completely remove biocude color while colorless biocrude was obtained with $50 \mathrm{mg} / \mathrm{ml}$ activated charcoal treatment for 12 hours. Equal volumes $(1 \mathrm{ml})$ of untreated biocrude and AC-treated samples were tested for photocatalytic $\mathrm{H}_{2}$ generation using $0.4 \mathrm{mg} / \mathrm{ml} \mathrm{Pt} / \mathrm{TiO}_{2}$ catalyst concentration. 
The gas phase $\mathrm{H}_{2}$ volume (ml at NTP) was estimated for $150 \mathrm{ml}$ biocrude. As seen from Figure 3, PR of untreated biocrude did not generate any $\mathrm{H}_{2}$ whereas $10 \mathrm{mg} / \mathrm{ml}$ and $50 \mathrm{mg} / \mathrm{ml} \mathrm{AC-treated} \mathrm{biocrude} \mathrm{generated} 0.6 \mathrm{ml}$ and 2.14 $\mathrm{ml}$ of $\mathrm{H}_{2}$, respectively after $180 \mathrm{~min}$.

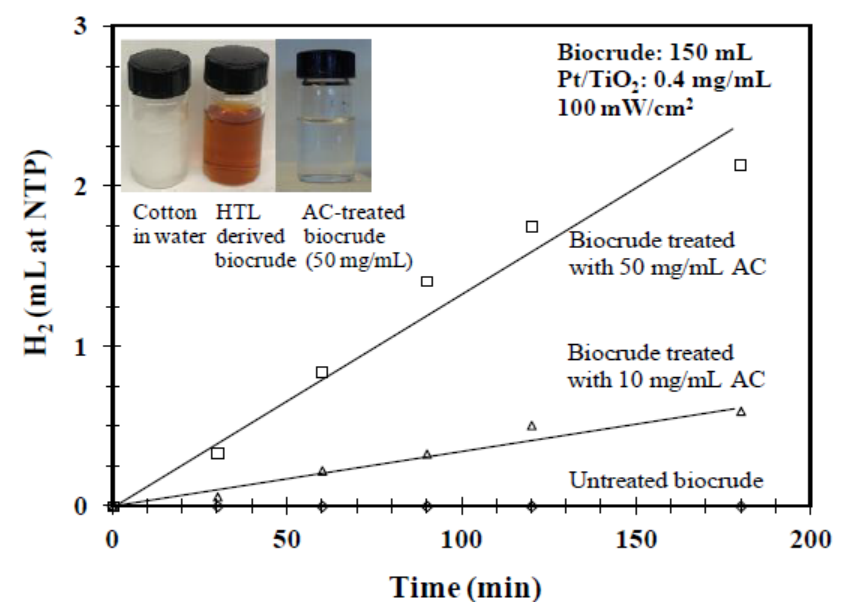

Figure 3. $\mathrm{H}_{2}$ volume generated during PR of untreated cotton biocrude and biocrude treated with activated carbon at different concentrations

Although the colorless biocrude provided a six fold increase in $\mathrm{H}_{2}$ volume generation, increasing $\mathrm{AC}$ concentration to $50 \mathrm{mg} / \mathrm{ml}$ contributed to loss of the $\mathrm{C}$ and $\mathrm{H}$ content of the biocrude. HPLC analysis of AC-treated cotton biocrude (Table 1) indicates significant removal of $\mathrm{C}_{1}-\mathrm{C}_{3}$ carboxylic acids as compared to the untreated biocrude. Alternate methods to selectively remove only the interfering compounds without affecting the carboxylic acids and sugars are currently under investigation. It can also be noticed from Table 2 that several oxygenated hydrocarbon compounds including the major ones such as 1H-pyrazole, 1,5-dimethyl-, 1,23-benzenetriol, 1,2,4 benzenetriol and 1,2 cyclopentanedione, 3-methyl have been removed by the AC treatment. It is to be noted that the AC has significant Ni ions adsorption capacity (97.8\%) [18]; therefore, we inferred that negligible Ni ions were present during PR of AC-treated biocrude.

\subsection{Photocatalysis of Biocrude Component and AC-treated Biocrude}

Acid

To further understand the role of the four major acid components of the biocrude towards the $\mathrm{H}_{2}$ production, photoreforming of $50 \mathrm{mM}$ LA, AA, FA and PA was carried out using procedure outlined in the Experimental section. Clearly, as seen from Figure 4 the acids differ in relative proficiencies as electron donors. Formic acid which is structurally simplest $\mathrm{C}_{1}$ acid with one $\alpha$ hydrogen appears to be best electron donor producing maximum $\mathrm{H}_{2}$ volume during 180 min reaction time. Under identical PR conditions, formic acid yielded $9.7 \mathrm{ml} \mathrm{H}_{2}$ at NTP, which was 133 fold, 12.77 fold, and 2.95 fold higher than AA, PA and LA, respectively. LA, which is major acid in the biocrude, is also a better electron donor compared with the other two $\mathrm{C}_{1}-\mathrm{C}_{3}$ acids. On the other hand, acetic acid is relatively recalcitrant to photoreforming to $\mathrm{H}_{2}$. $\mathrm{LA}$, a $\mathrm{C}_{3}$ acid differs from PA by the presence of a single hydroxyl group. The hydroxyl group in addition to the carboxyl group probably increases adsorption affinity of LA on the $\mathrm{TiO}_{2}$ surface. This could facilitate better transfer of the photogenerated electrons to LA generating higher $\mathrm{H}_{2}$ yields. A mixture containing $50 \mathrm{mM}$ of FA, AA, PA and LA was also investigated for $\mathrm{H}_{2}$ generation under identical PR conditions. Although the total $\mathrm{H}_{2}$ content of this mixture was higher, the $\mathrm{H}_{2}$ volume generated $(6.65 \mathrm{~mL}$ ) was about 1.5 fold lower than produced by the FA during PR, however, it was higher than LA, PA, and AA. This suggests that recalcitrant acids such as AA and PA in the acid biocrude probably reduce $\mathrm{H}_{2}$ generation. This warrants further investigation of $\mathrm{Pt} / \mathrm{TiO}_{2}$ surface reactions of acid mixture during PR. In a separate experiment LA, $\mathrm{PA}, \mathrm{AA}$ and FA were mixed in the concentration ratio found in the cotton biocrude. This acids mixture is referred to as 'biocrude acid simulant'. During 180 min of $\mathrm{PR}$ reaction, $1.16 \mathrm{~mL} \mathrm{H}_{2}$ was generated from the biocrude simulant. The biocrude stimulants were prepared with 0.1 and 10 fold acids concentrations to study the effect of concentration on $\mathrm{H}_{2}$ evolution. The 0.1 fold biocrude stimulant generated significantly higher $\mathrm{H}_{2}$ volume $(4.13 \mathrm{~mL})$, whereas 10 -fold biocrude stimulant generated only $0.8 \mathrm{ml}$ at NTP during PR. As the catalyst loading was held constant $(0.4 \mathrm{mg} / \mathrm{ml})$, higher number of active sites were available for the acid moieties present in 0.1 fold biocrude stimulant, which reflected into higher $\mathrm{H}_{2}$ volume generation.

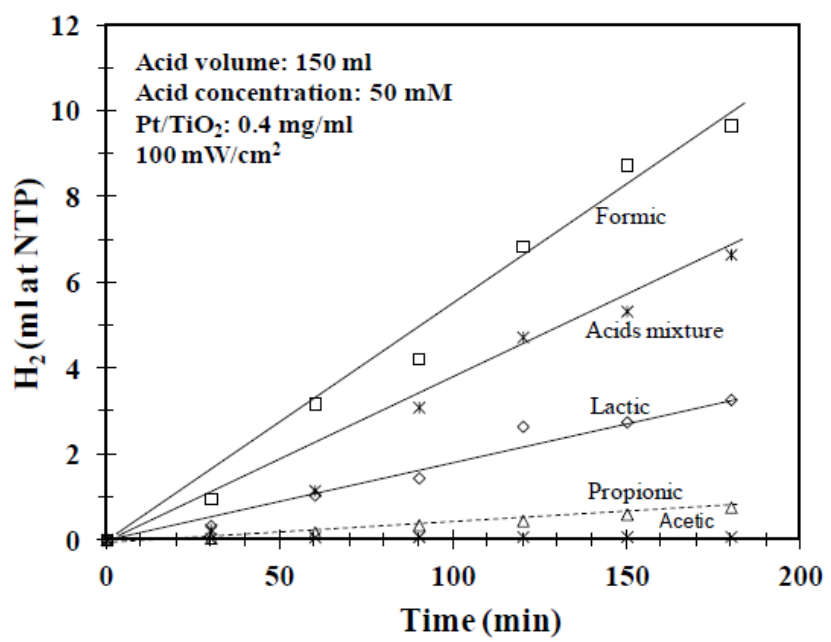

Figure 4. Comparative $\mathrm{H}_{2}$ volume generated during $\mathrm{PR}$ of carboxylic acids and their mixture

It can be concluded that under the experimental conditions employed in this study, $\mathrm{NiSO}_{4}$ catalyzed HTL process generates sufficient quantities of acids ( $79 \mathrm{wt} \%$ ) in the downstream biocrude. The biocrude can be used without dewatering or concentrating the acids for PR to enhance $\mathrm{H}_{2}$ generation.

\subsection{Combined Yields of $\mathrm{H}_{2}$ from Integrated HTL and PR Processing of Cotton}

To investigate total $\mathrm{H}_{2}$ volume generation capacity of the biocrude simulant and actual biocrude during PR, multiple PR cycles were performed in the time interval of 180 min. After 180 min of $\mathrm{PR}$ reaction, the reactor headspace was evacuated by purging with $\mathrm{N}_{2}$ until $\mathrm{H}_{2}$ was undetectable in the GC analysis. The reactor was again exposed to simulated solar irradiation and next PR cycle was performed for $180 \mathrm{~min}$. The $\mathrm{H}_{2}$ volume generated from the biocrude acid simulant during four PR cycles is shown in Figure 5a. During PR cycle-1, cycle-2, cycle-3 and cycle-4, the maximum $\mathrm{H}_{2}$ volume of $5.35 \mathrm{ml}, 3.75 \mathrm{ml}$, $1.98 \mathrm{ml}$, and $0.75 \mathrm{ml}$, respectively was observed after 180 
min reaction time. The $\mathrm{H}_{2}$ volume generated from the actual biocrude during four PR cycles is shown in Figure $5 \mathrm{~b}$. The maximum $\mathrm{H}_{2}$ volume observed during PR cycle-1, cycle-2, cycle- 3 and cycle- 4 was $2.17 \mathrm{ml}, 1.6 \mathrm{ml}, 0.87 \mathrm{ml}$ and $0.56 \mathrm{ml}$, respectively. These results indicate lower $\mathrm{H}_{2}$ volume generation from the actual biocrude as compared with the biocrude acid simulant, which infers that the additional oxygenated compounds (Table 2) present in actual biocrude probably inhibited some of the $\mathrm{H}_{2}$ generating reactions. The volumes of $\mathrm{H}_{2}$ generated from each PR cycle were combined to obtain the total $\mathrm{H}_{2}$ volume.
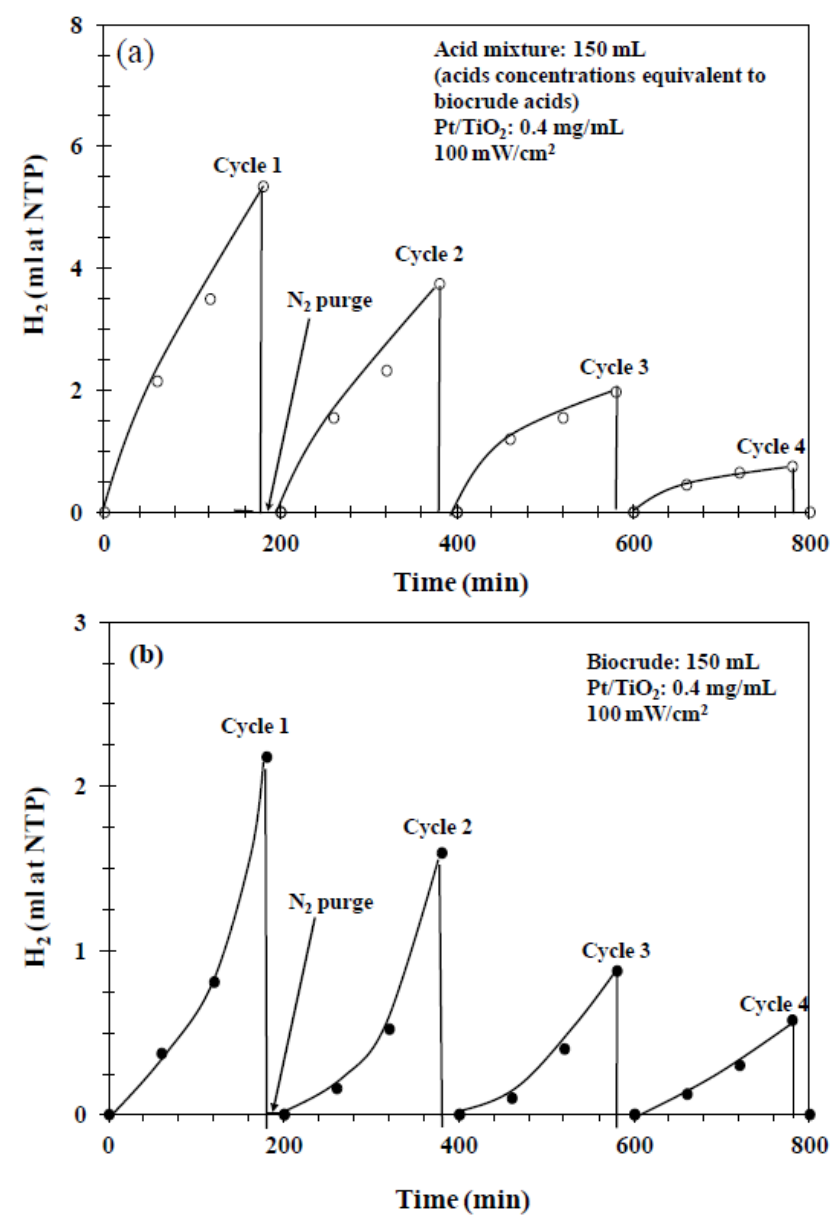

Figure 5. a: $\mathrm{H}_{2}$ volume generated during $\mathrm{PR}$ of $\mathrm{C}_{1}-\mathrm{C}_{3}$ acids mixture, and b) AC-treated cotton biocrude

The $\mathrm{H}_{2}$ yield (vol\%) was determined as per the following equation-

$$
\begin{aligned}
& H_{2} \text { yield } \\
& =\frac{\sum\left(H_{2} \text { volume generated in each cycle }\right)}{\left(\begin{array}{l}
\text { total theoretical } H_{2} \text { volume } \\
\text { of all acids present in mixture }
\end{array}\right)} \times 100
\end{aligned}
$$

The total $\mathrm{H}_{2}$ volume of acids mixture was estimated based on the theoretical $\mathrm{H}_{2}$ content of all acids and their concentrations used to prepare the acids mixture. For biocrude, the $\mathrm{H}_{2}$ yield was determined as the ratio of total $\mathrm{H}_{2}$ volume generated in all $\mathrm{PR}$ cycles and $\mathrm{H}_{2}$ volume content of $150 \mathrm{ml}$ AC-treated biocrude. The total $\mathrm{H}_{2}$ volume for the AC-treated biocrude was estimated based on the acids concentration reported in Table 1 . These acids were present in the biocrude after AC treatment. The $\mathrm{H}_{2}$ yields in terms of vol\% are presented in Figure 6. It shows a total $\mathrm{H}_{2}$ vol\% produced from actual biocrude during four PR cycles was $17.82 \%$. When $\mathrm{H}_{2}$ vol\% from PR and HTL

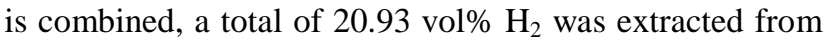
cotton biocrude. This shows that by integrating HTL and $\mathrm{PR}$ processes, higher $\mathrm{H}_{2}$ volume generation could be achieved. A maximum of 57.5 vol\% $\mathrm{H}_{2}$ was observed from biocrude acid simulant that contained only carboxylic acids during four PR cycles. This leads to the notion that the acids can be separated from the biocrude and treated with $\mathrm{PR}$ for higher $\mathrm{H}_{2}$ volume generation.

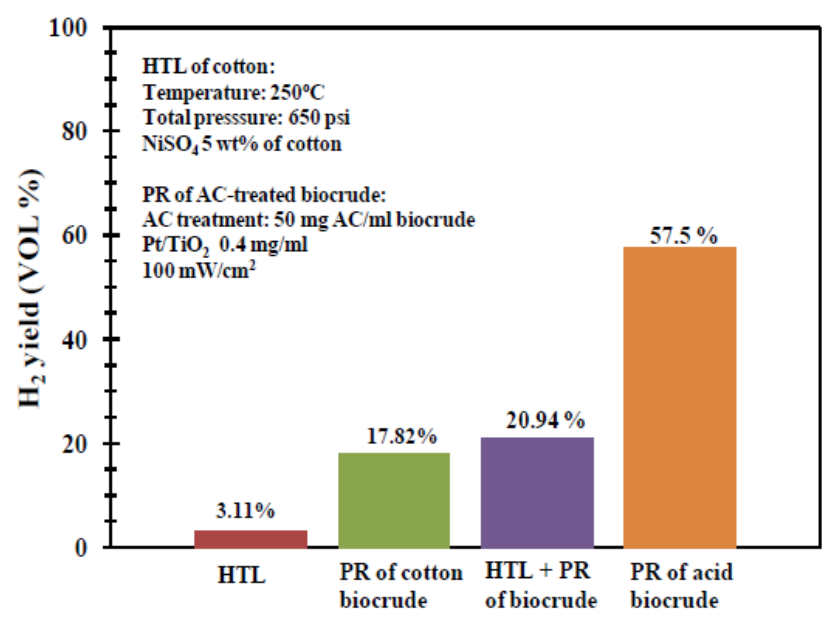

Figure 6. Total $\mathrm{H}_{2}$ (vol\%) extracted by integrating HTL of biomass and PR of HTL derived biocrude

\section{Conclusions}

$\mathrm{HTL}$ of cotton at $250^{\circ} \mathrm{C}$ in presence of $\mathrm{NiSO}_{4}$ yielded $10 \mathrm{wt} \%$ product gas, $61.2 \mathrm{wt} \%$ liquefied biocrude and 28.8 wt\% char. The product gas phase during HTL was found to contain 3.12 vol\% $\mathrm{H}_{2}$ whereas the PR of biocrude performed during cycles 1 to 4 amounts to a total of 5.22 ml. When the $\mathrm{H}_{2}$ volume generated from HTL was combined with the total $\mathrm{H}_{2}$ volume produced during four PR cycles, a total of 20.94 vol\% was extracted from the biocrude. Thus by integrating HTL and PR, higher $\mathrm{H}_{2}$ volume generation could be achieved.

\section{Acknowledgement}

Authors acknowledge the financial and research assistantship support from NSF EPS-0903804 and Chemical and Biological Engineering at South Dakota School of Mines \& Technology.

\section{References}

[1] Lewis, N., "Powering the Planet”, MRS Bulletin, 32 (10). 808- 820. 2007.

[2] Rittmann, S., and Herwig, C., "A comprehensive and quantitative review of dark fermentative biohydrogen production”, Microbial Cell Factories, 11 (1.). 115-133. 2012.

[3] Wang, D., Czernik, S., Montane, D., Mann, M., and Chornet, E., "Biomass to hydrogen via fast pyrolysis and catalytic steam reforming of the pyrolysis oils or its fractions", Industiral \& Engineering Chemistry Research, 36 (5). 1507-1518. 1997.

[4] Elliot, D.C., Neuenschwander, G.G., Hart, T.R., Butner, R.S., Zacher, A.H., Engelhard, M.H., Young, J.S., and McCready, D.E., 
"Chemical processing in high-pressure aqueous environments. 7. Process development for catalytic gasification of wet biomass feedstocks”, Industiral \& Engineering Chemistry Research, 43 (9). 1999-2004. 2004

[5] Tungal, R., and Shende, R.V., "Subcritical aqueous phase reforming of wastepaper for biocrude and $\mathrm{H}_{2}$ generation”, Energy \& Fuels, 27 (6). 3194-3203. 2013.

[6] Tungal, R., and Shende, R.V., "Hydrothermal liquefaction of pinewood (Pinus ponderosa) for $\mathrm{H}_{2}$, biocrude and bio-oil generation”, Applied Energy, 134. 401-412. 2014.

[7] Kondarides, D.L., Daskalaki, V.M., Patsoura, A., and Verykios X.E., "Hydrogen production by photo-induced reforming of biomass components and derivatives at ambient conditions", Catalysis Letters, 122. 26-32. 2008.

[8] Fu, X., Long, J., Wang, Z., Leung, D.Y.C., Ding, Z., Wu, L., Zhang, Z., Li, Z., and Fu, X., "Photocatalytic reforming of biomass: A systematic study of hydrogen evolution from glucose solution”, International Journal of Hydrogen Energy, 33 (22), 6484-6491. 2008.

[9] Tungal, R., Shende, R.V., and Christopher, L., "Nickel catalyzed high pressure hydrothermal processing of biomass for $\mathrm{H}_{2}$ production”, Journal of Energy Power Engineering, 5. 504-514. 2011.

[10] Li Y, Lu G, Li S. Photocatalytic production of hydrogen in single component and mixture systems of electron donors and monitoring adsorption of donors by in situ infrared spectroscopy. Chemosphere. 2003 Aug; 52(5):843-50.

[11] Lanese, V., Spasiano, D., Marotta, R., Sommar, I.D., Lisi, L., Cimio, S., Andreozzi, R., 2013. Hydrogen production by photoreforming of formic acid in aqueous copper $/ \mathrm{TiO}_{2}$ suspensions under UV-simulated solar radiation at room temperature, Int. J. Hydrogen Energy, 23, 9644-9654.

[12] Heciak,A, Morawski, A Grzmil, B, Mozia, S August-September 2013; $\mathrm{Cu}$ modified $\mathrm{TiO}_{2}$ photocatalysts for decomposition of acetic acid with simultaneous formation of $\mathrm{C}_{1}-\mathrm{C}_{3}$ hydrocarbons and hydrogen Applied Catalysis B: Environmental; Volumes 140141,108-114.

[13] Maraschi, Daniele Dondi, Andrea Serra, Antonella Profumo, Armando Buttafava, Angelo Albini Swine sewage as sacrificial biomass for photocatalytic hydrogen gas production: Explorative study Andrea Speltini, Michela Sturini, Federica International journal of hydrogen energy 39 (2014) 11433 e11440

[14] Ela Ero glua, 'Inci Ero glua, Ufuk Gündüzb, Lemi Türkerc, Meral Yücelb Biological hydrogen production from olive mill wastewater with two-stage processes International Journal of Hydrogen Energy 31 (2006) 1527-153.

[15] Mohan, S.V., and Karthikeyan, J., "Removal of lignin and tannin colour from aqueous solution by adsorption onto activated charcoal”, Environment Pollution, 97 (1-2). 183-187. 1997.

[16] Mudoga, H.L., Yucel, H., and Kincal, N.S., "Decolorization of sugar syrups using commercial and sugar beet pulp based activated carbons”, Bioresource Technology, 99 (9). 3528-3533. 2008.

[17] Orozco, R.L., Redwood, M.D., Leeke, G.A., Bahari, A., Santos, R.C.D., and Macaskie, L.E., "Hydrothermal hydrolysis of starch with $\mathrm{CO}_{2}$ and detoxification of the hydrolysates with activated carbon for bio-hydrogen fermentation”, International Journal of Hydrogen Energy, 37 (8). 6545-6555. 2012.

[18] Hashimoto, K., Irie, H., and Fujishima, A., " $\mathrm{TiO}_{2}$ photocatalysis: a historical overview and future prospects”, Japanese Journal of Applied Physics, 44 (12). 8269-8285. 2005.

[19] Hussein, A.M., and Shende, R.V., "Enhanced hydrogen generation using $\mathrm{ZrO}_{2}$-modified coupled $\mathrm{ZnO} / \mathrm{TiO}_{2}$ nanocomposites in the absence of noble metal co-catalyst”, International Journal of Hydrogen Energy, 39 (11). 5557-5568. 2014.

[20] Ni, M., Leung, M.K.H., Leung, D.Y.C., and Sumathy, K., “A review and recent developments in photocatalytic water-splitting using $\mathrm{TiO}_{2}$ for hydrogen production”, Renewable \& Sustainable Energy Reviews, 11. 401-425. 2007.

[21] Rossetti, I., "Hydrogen production by photoreforming of renewable substrates”, ISRN Chemical Engineering. 1-21. 2012.

[22] Hasar, H., "Adsorption of nickel (II) ions from aqueous solution onto activated carbon prepared from almond husk”, Journal of Hazardous Materials, 97 (1-3). 49-57. 2003.

[23] Yin, S., Tan, Z., 2012. Hydrothermal liquefaction of cellulose to bio-oil under acidic, neutral and alkaline conditions, Applied Energy, 92 (C), 234-239. 